\title{
TREATMENT OF CHOREA BY NIRVANOL
}

\author{
BY \\ HUGH T. ASHBY, M.I)., F.R.C.P. \\ (From the Royal Manchester Children's Hospital, Pendlebury.)
}

I am indebted to Poynton and Schlesinger ${ }^{1}$ for the suggestion that nirvanol should be given a trial in the treatment of chorea. Twelve well marked cases have been treated with this drug alone, and the results are encouraging in that all the cases have done well and the course of the disease has been shortened.

All the cases were in hospital and under close supervision in bed the whole time. No unfavourable symptoms developed, except in one child, who reacted rather severely. This was a particularly nervy child with very marked chorea. She did remarkably well in the end.

Nirvanol is a white powder, tasteless and readily taken by children. One dose each day is given, generally in the evening. The dose administered was $3 \frac{1}{2}$ grn. to children up to the age of 10 years and 4 grn. to older ones.

After about 8 daily doses a rash appears and the drug is stopped at once and no treatment other than rest in bed is undertaken.

Eight days seems to be the average for the rash to appear. In one case in which the rash was particularly well marked it appeared on the fifth day. The rash was nor accompanied by any rise of temperature, except in the case mentioned, when it came on the fifth day.

Some of the children, especially the girls, were noticed to be incontinent of urine the evening before the rash appeared, and the onset of the rash could be forecast by this phenomenon. The incontinence lasted for a few hours only and had disappeared by the next morning.

The rash nearly always started on the back of the hands or on the buttocks, and then spread to the trunk. Pressure points such as the elbows and buttocks were specially affected. There was practically no rash on the face. The rash is visible for about four days. It is faintly visible for one day, is well marked for two days, and takes one day to fade and completely disappear. It is essentially toxic in appearance and varies in intensity on the different parts of the body within a short time. While painting the rash for me, Miss Davidson noticed this characteristic and corroborated the fact on her own observation.

The rash is very slightly raised and can just be felt. It is morbilliform and like measles except that the papules are liable to become more confluent. In fact anyone seeing a nirvanol rash would at once say that the case was one of measles. 


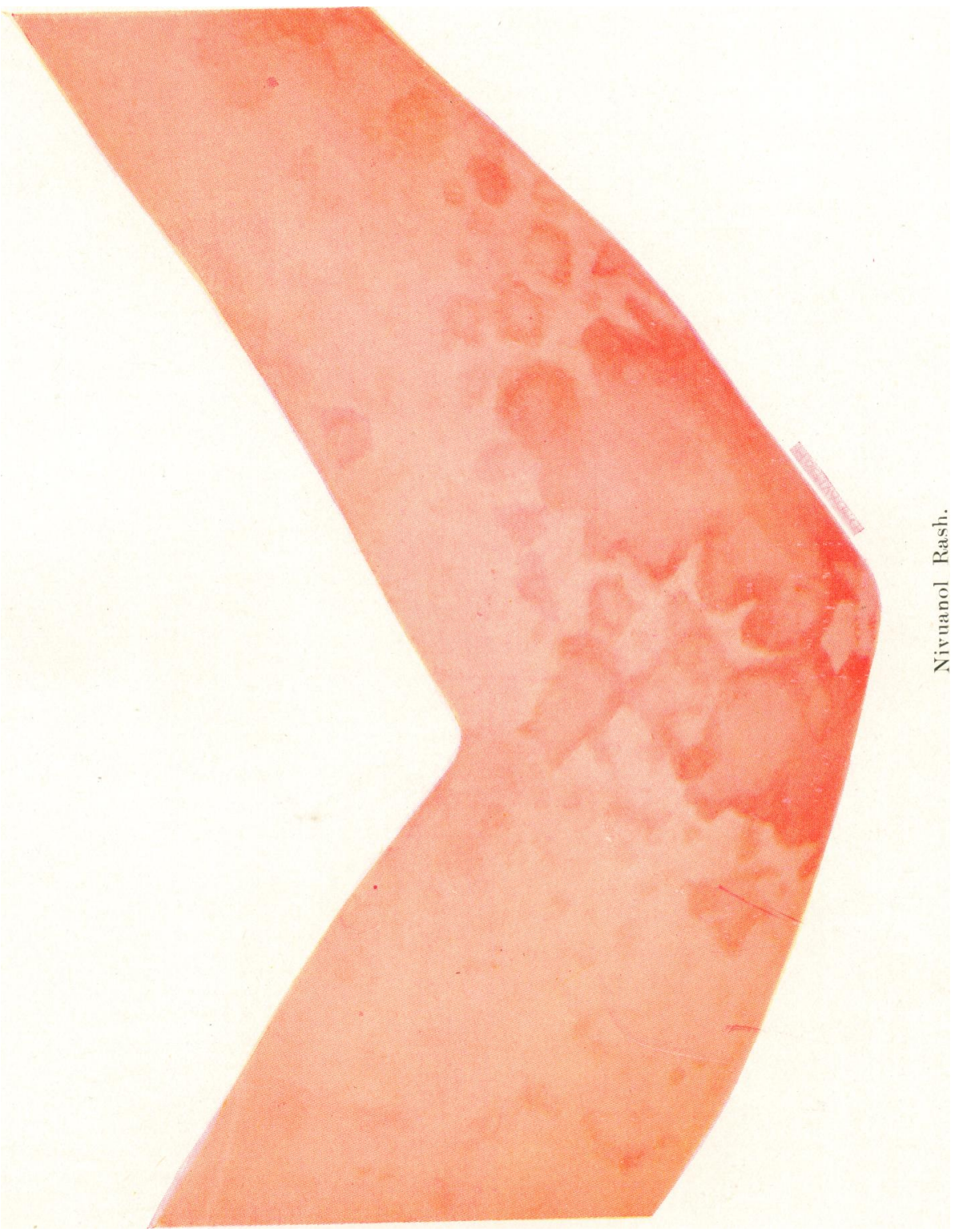

o ज্ 
The children were not inconvenienced in any way by the rash, the pulse rate was hardly increased and there was no irritation. In a few cases there was a slight conjunctivitis during the period of the rash, but no other complications were noticed. The urine was always free from albumen.

An interesting point was that some of the children lost the knee jerks at about the time the rash appeared, and they did not return for a few days. The choreiform movements were slightly aggravated at this time, but they quickly settled down and disappeared.

The heart lesions, present in a few cases, were not adversely affected: in fact rather the opposite was found.

Like Poynton and Schlesinger's cases, there was a marked increase in the eosinophils of the blood at the rash period. A week later the blood became normal.

\section{Conclusions.}

The treatment of chorea by nirvanol appears to be safe as long as the child is kept under close observation and the dose does not exceed 4 grn. a day.

The general course of the disease is shortened and improvement is more speedy than with other methods usually adopted. At the end of the third week the children were steady and ready to leave hospital, and there have been no relapses so far.

A point in favour of nirvanol is that the chorea may be checked before the sheumatic infection does harm to the heart.

Severe secondary reactions have been reported after exposure to artificial sunlight just after children had finished a course of nirvanol, and this latter should not be given until some weeks have elapsed.

\section{REFERENCES.}

1. Poynton, F. J., \&. Schlesinger, B. E., Lancet, Lond., 1929, ii, 267. 